\title{
Statistical Analysis of Attitude and Behavior of Youths on the "Other" in Granada City (Andalusia, Spain)
}

\author{
José A. Esquivel*,a,b, Francisco Jiménez ${ }^{\mathrm{b}, \mathrm{c}}$, Francisco J. Esquivel ${ }^{\mathrm{d}}$ and José A. Esquivel-Sánchez \\ ${ }^{a}$ Department of Prehistory and Archaeology, University of Granada, Spain \\ ${ }^{b}$ Institute of Peace and Conflicts, University of Granada, Spain \\ ${ }^{c}$ Department of Social Anthropology, University of Granada, Spain \\ ${ }^{d}$ Department of Statistics and Operations Research, University of Granada, Spain
}

\begin{abstract}
The recent process of immigration, mainly since 2001, represents a serious integration problem for the society of Granada (Spain) due to the great increase of immigrants in the last years. The viewpoint of the young people in the city of Granada (from 14 to 25 years) is key with regard to future trends. These youths need to learn how to share and compete for the new economic niches inside the society of Granada, a situation aggravated by the economic crisis. This scenario presents increasing levels of racism and xenophobia at the moment.

In this paper, using a statistical analysis of opinion polls, we examine the influence of the human diversity, i.e. migrants living in Granada, holding jobs and studying, etc. These analyses enable us to outline the way in which youths regard foreigners, in order to understand and characterize how the phenomenon of the immigration will be perceived over the long term within the society Granada.
\end{abstract}

Keywords: Diversity, Granada City, Migrations, Racism, Statistical Analysis, Youths.

\section{INTRODUCTION}

Immigration has been increasing in Spain from the late 1980 s, increasing strong interest among social workers, researchers, politicians, and others. This influx of people has gained surprising coverage in the mass media, perhaps for being a new phenomenon in Spain, a country that traditionally sent emigrants to other countries of Europe, but that recently has become the destination of immigrants. The history of migrations in Europe was dominated by the migrants to no European countries over the 20th century [1], and these flows ended because of the 1973 world oil crisis. In Spain, internal transformations (economic boom from the building and tourism), and the incorporation of Spain to the UE brought home most of the Spanish immigrants [2]. However, the big countries in the world with more than 20 million inhabitants have the highest percentages of immigrants with respect to its entire population: Saudi Arabia (26\%), Australia (20\%), Canada (19\%) and USA (13\%), but small countries such as Spain and France have 11\% of immigrants. Spain is the country in the world having the greatest increase in immigration, from 0.6 millions of immigrants in 1990 to 4.8 million in 2005 [3]. Today, immigrants to Spain form two major groups. First are the immigrants of countries with high economic development, and their arrival is linked to the growth of the Spanish economy, goods and services mainly. The second group is formed by people from countries with lower economic levels than in Spain, and their

*Address correspondence to this author at the Institute of Peace and Conflicts, Centro de Documentación Científica, Rector López Argüeta, s/n 18071 - Granada Andalusia, Spain; Tel: +34958244142; Fax: +349588974; E-mail: esquivel@ugr.es arrival is linked to the limited employment opportunities and poor economic situation in their countries of origin. This group is a majority of immigrants, comprising people from Eastern Europe, Africa, Latin America, and Asia [4, 5]. Many studies have examined the determinants of individual attitudes toward immigration [6], the relationship between immigration and welfare $[7,8]$, the way in which immigrants affect the job market [9], the relations between immigrants and host societies [10], as well as discrimination towards immigrants with regard to jobs in Spain [11].

According to the latest documentation by the European Observatory of Racism and Xenophobia located in Vienna (Austria), the society of Granada (Spain) associates immigration with delinquency and terrorism, due mainly to the great number of Islamic immigrants in Granada [12-14]. The inhabitants of Granada are becoming less tolerant towards immigrants, this being reflected in some racist and extremeright-wing aggression, which is very scarce (only one occurrence) but with great mass-media repercussions. In the present work, we carried out opinion polls in 1996, 2000, 2004, and 2008, according to the conventions of the European Observatory of the Racism and Xenophobia, identifying a small but growing trend of increasing insecurity among citizens of the city of Granada, partly from fear of bands and urban gangs. These perceptions are associated with many factors, such as the illegal immigration, the relocation of many companies in other countries, unemployment, and the competition between Spanish natives and immigrants to get a job, the issues that arise in periods of unemployment due to the seasonal nature of the jobs, and the emergence of conflicts between certain groups of immigrants (from Central America and Central Europe mainly). This situation has been ex- 
Table 1. Technical Features of the Interviews

\begin{tabular}{|l|l|}
\hline Scope & Granada City \\
\hline Population & 50,000 youths $14-25$ years old and 20,000 foreign students $17-27$ years old \\
\hline Sample & Random sample $\mathrm{n}=400$ each period, $\pm 5 \%$ sample error for $95.5 \%(2 \sigma)$ significance level and distribution parameters $\mathrm{p}=\mathrm{q}=0.5$ \\
\hline Sampling & Random stratified for municipal districts with sex and age quotas \\
\hline Typology & Home survey by means personally interviewing people $14-25$ years old \\
\hline Fieldwork & March $18-301996$ February $1-182000$ November $10-302004$ April $1-262008$ \\
\hline
\end{tabular}

acerbated due to the current economic world crisis, provoking resentment towards illegal immigration [15-17]. In this paper, we present the opinion poll carried out to analyse the reasons for aversion to immigrants, to identify their country origins, and to discover their living environment in Granada. The ultimate aim was to ascertain the way youths perceive the foreign element in Granada.

\section{MATERIALS AND METHODOLOGY}

Using the interview European Observatory of the Racism and the Xenophobia model, we conducted research on the following technical characteristics (Table 1).

The files used were the Municipal Poll of Inhabitants, the Andalusian Institute of Statistics, and the EUROSTAT (European Statistics). Also, any data were obtained from the files of the Andalucía Acoge (Andalusian Federation of Centres of Immigrant Reception).

In recent years, a great number of migrants have entered Spain, and the quantity of foreign people has soared from 250,000 in 2001 to $4,000,000$ persons in 2005 [10]. The usual categories to measure immigration are "foreign people", "naturalized people" and "returning people". The largest group was composed of foreigners, with $91.32 \%$ in 2001 and $91.40 \%$ in 2005 [17]. In addition, the age of immigrants shows that the most foreign people are 20-25 years old, following a Gaussian bell-curve distribution, while returning people had two different peaks (25-35 years old, and 60-77 years old). Presumably, the second peak corresponds to the Spanish who emigrated primarily to affluent European countries in the 1960s Fig. (1). Graphs showing the differences between types of immigration based in age (OX axis). The number of foreign men was greater than women, but with similar features: both populations fit a normal distribution, the greater percentages belonging to the 21-36 age group. There were no differences in the naturalized category, while the numbers of persons in each age category were similar for both sexes. Finally, the group of returning was similar for men and women, reproducing the results in Fig. (1): one peak corresponds to retired persons and the other to the sons who returned with their retired parents. The immigrants were from several countries. In 2005, the countries with the greatest number of immigrants $(62.7 \%)$ were Morocco and Romania (154,077 and 149,995 persons, respectively) followed by Ecuador $(65,673$ persons), Bolivia $(63,342)$, Colombia $(61,767)$, United Kingdom $(53,613)$, Argentina $(49,254)$, China $(37,429)$, Brazil $(33,563)$ and Peru $(31,527)$ (Fig. 2). Most of immigrants were from Latin America and the Maghreb, seeking jobs. Immigrants from the United Kingdom were retired people living almost year round in Spain due to the climate $[11,18]$ Fig. (2). Countries of origin of the greatest number of immigrants in 2005 (Spanish National Institute of Statistics).

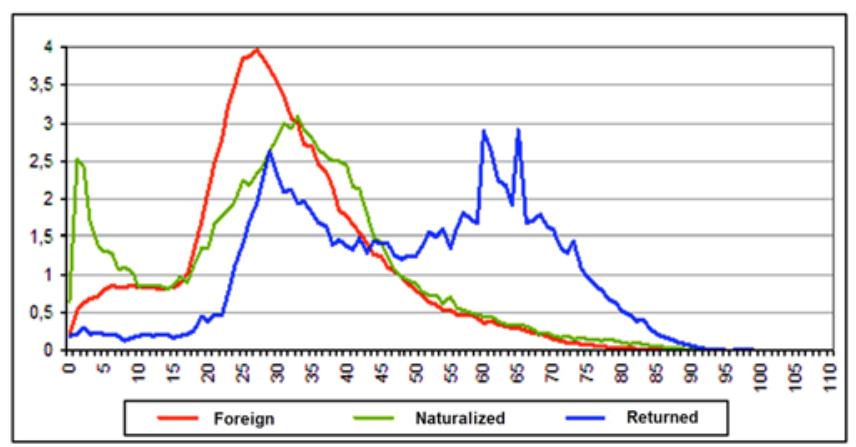

Fig. (1). Graphs showing the differences between types of immigration based in age (OX axis).

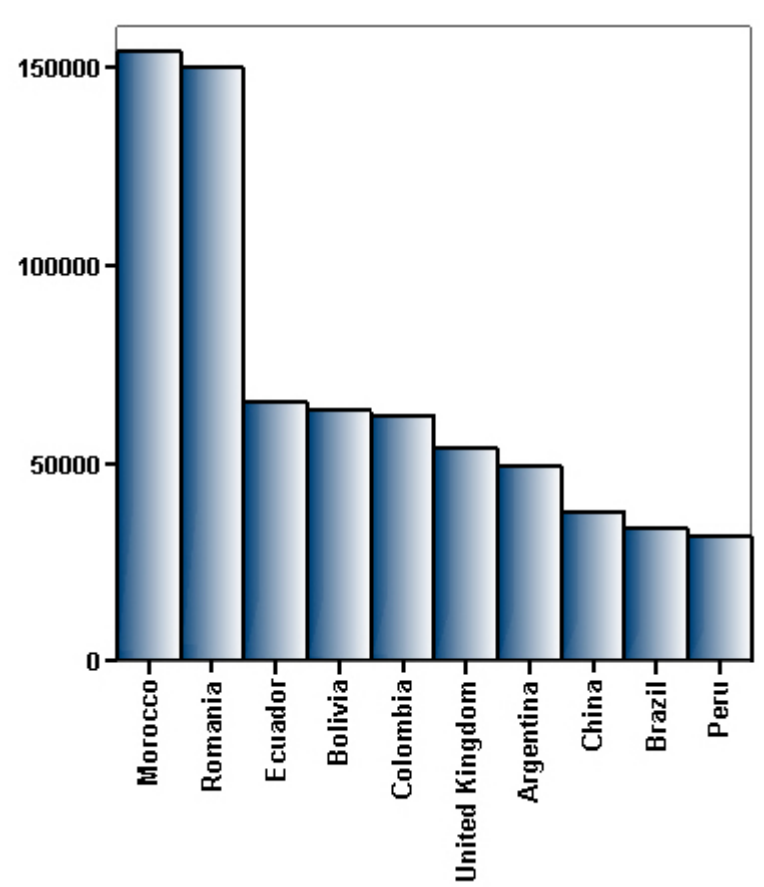

Fig. (2). Countries of origin of the greatest number of immigrants in 2005 (Spanish National Institute of Statistics).

From the data set, we took a random sample of youths in Granada City to identify the features of "the other", i.e., people living in the city of Granada and having different characteristics from the majority of the inhabitants. Questions in 
the interview were expressed as open questions trying to determine the "otherness" by means out five categories of social characteristics: nationality, race, language, culture and social class. Also, we added a new question expressed as "When you hear speaking about persons with different nationality, race, religion, culture or social class, about whom does he think?" to evaluate the perception of the Granada youths about foreigners.

\section{THE ORIGIN OF THE IMMIGRANTS}

First, we analysed the data compiled in the new questionnaire focused on the immigrants' place of origin in the world. This factor is perceived in different ways (Table 2). The percentages were very low and it was not possible to apply statistical methods as $\chi^{2}$. The Wilcoxon nonparametric test showed statistical significant differences between 2008 and the other years with a significance level $\alpha<0.05$, but there were no statistical differences between 1996,2000 , or 2004. It is important to emphasize the decrease of immigrants from Central and North Africa and the rise in immigrants from other countries, mainly from Latin America, whereas 2008 shifted the immigration trend. The presence of immigrants from Latin American, Asia and Europe became noticeable, the index increasing by $600 \%$ and $400 \%$, respectively. These characteristics have altered the perception of "otherness" in the last few years $[13,19]$. The first question to evaluate the opinion of the youths concerning the quantity of persons perceived as "foreign" was: "How do you rate the number of persons of another nationality, race, religion, culture, or social class living in our city?". The possible responses were qualitative variables classified in the following categories: "too many", "many but not too many", "not many", and "do not know (NK)" / "no answer (NA)".

Table 2. Summary of the Percentages from 1996 to 2008

\begin{tabular}{|c|c|c|c|c|}
\hline & $\mathbf{1 9 9 6}$ & $\mathbf{2 0 0 0}$ & $\mathbf{2 0 0 4}$ & $\mathbf{2 0 0 8}$ \\
\hline \hline North Africa & 68.7 & 70.5 & 72.0 & 47.1 \\
\hline Central Africa & 25.4 & 12.8 & 10.8 & 7.3 \\
\hline North American & 0.5 & 0.5 & 0.0 & 2.2 \\
\hline Latin American & 2.3 & 1.8 & 5.3 & 21.3 \\
\hline Asia & 0.8 & 1.3 & 1.0 & 6.1 \\
\hline Europe & 2.3 & 1.8 & 1.8 & 8.0 \\
\hline
\end{tabular}

The percentage of inhabitants of Granada who responded that there were "too many" immigrants was low $(<6.5 \%)$, while the other categories "many but not too many", "not many" registered a significant result: the perception of otherness grew over time in all categories, reflecting a shift in the perception of immigration. The graphs show an increasing trend over time in the perception of "many others", especially with respect to the social class. In recent years, the growth of otherness has been constant and in 2008 showed a sharp growth index, multiplying the percentages of 1996 by a factor 3 (Fig. 3). Perception of "many persons of another nationality, race, religion, culture, or social class living in our city" over time. The application of the $\chi^{2}$ test to percep- tion of otherness due to the nationality showed statistical differences with respect to sex $(\alpha<0.05)$ in 1996, 2000 and 2004 , with the women considered "not many" but men considered "many but not too many", whereas in 2008 no differences appeared between men and women $\left(\chi_{2}=1.438\right.$, $\mathrm{p}=0.868)$, reflecting a similar consideration towards men and women today. Also, there were no statistical significant differences with respect to the age of the interviewed, but the $\mathrm{p}$ value was at the limit of significance $\left(\chi_{2}=11.189, p=0.083\right)$ and thus did not give reliable results.

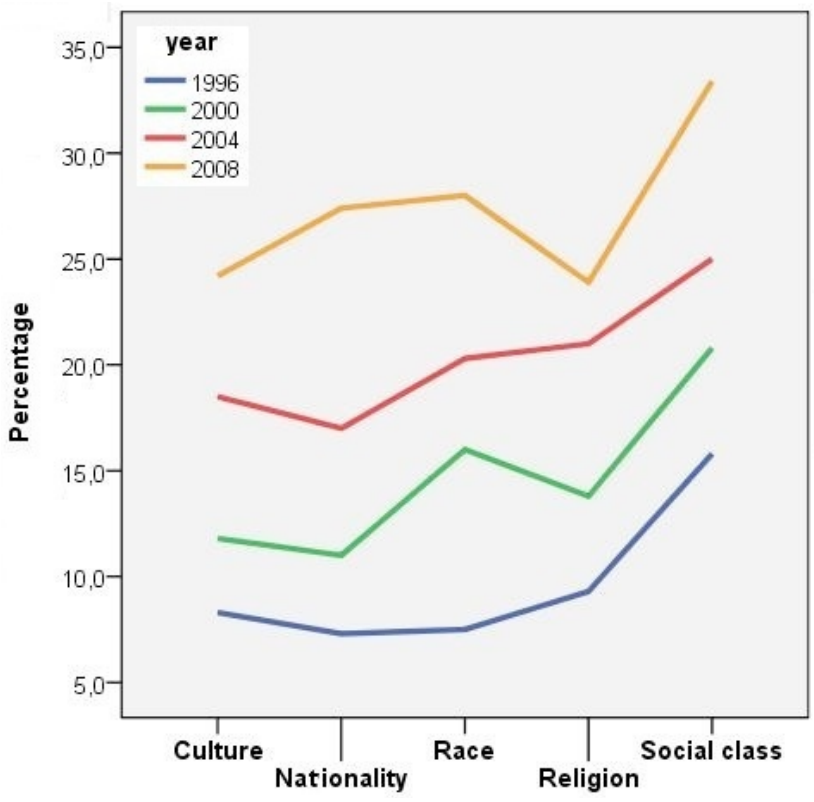

Fig. (3). Perception of "many persons of another nationality, race, religion, culture, or social class living in our city" over time.

\section{DAILY LIFE}

Daily life is an important topic because allow us to obtain information about how the perception of the immigrants may differ when they live in our neighbourhood as opposed to when they live far from our home. These daily contexts have been analysed from three perspectives that may be crucial for people to live together peaceably: a) immigrants living in near us, b) friendship with immigrants, and c) immigrants working or studying with us. The neighbourhood is important because it constitutes the nearest area of relationship, and it characterizes a important aspect of the otherness.

The first question posed was, "Do you think that there are many foreign people, few or none living in your neighbourhood?", and the results were the following: Fig. (4). Percentages for "many foreign people living in their neighbourhood", over time. The year 2000 showed an inflexion point, the percentages of otherness in all categories reached a minimum, and the percentages rose in the following years, thus indicating that the perception of otherness increased among the youths of Granada. Nationality was the item with the highest growth index (also exponential), close to race and culture, while religion and social class grew less. Social class appeared as the most influential category in otherness. The year 2008 was different, showing an increase in the response "too many" and a decrease in the response "few" with respect to the responses of 2004. Thus there was a general increase in the perception of otherness. By sex, the application 
of the $\chi^{2}$ test gave no statistical significant differences between men and women $\left(\chi^{2}=0.255, \mathrm{p}=0.880\right)$ with respect to the perception of otherness. Nor were there any differences with respect to age $\left(\chi_{2}=6.057, \mathrm{p}=0.417\right)$. The second question was "Have you many, few, or no foreign friends? This question indicates the level of integration of immigrants with the youths of Granada. This category implies the acceptance or rejection of the immigrant as an equal. The results appear in Fig. (5). Perception of "many immigrants" with respect to friendship.

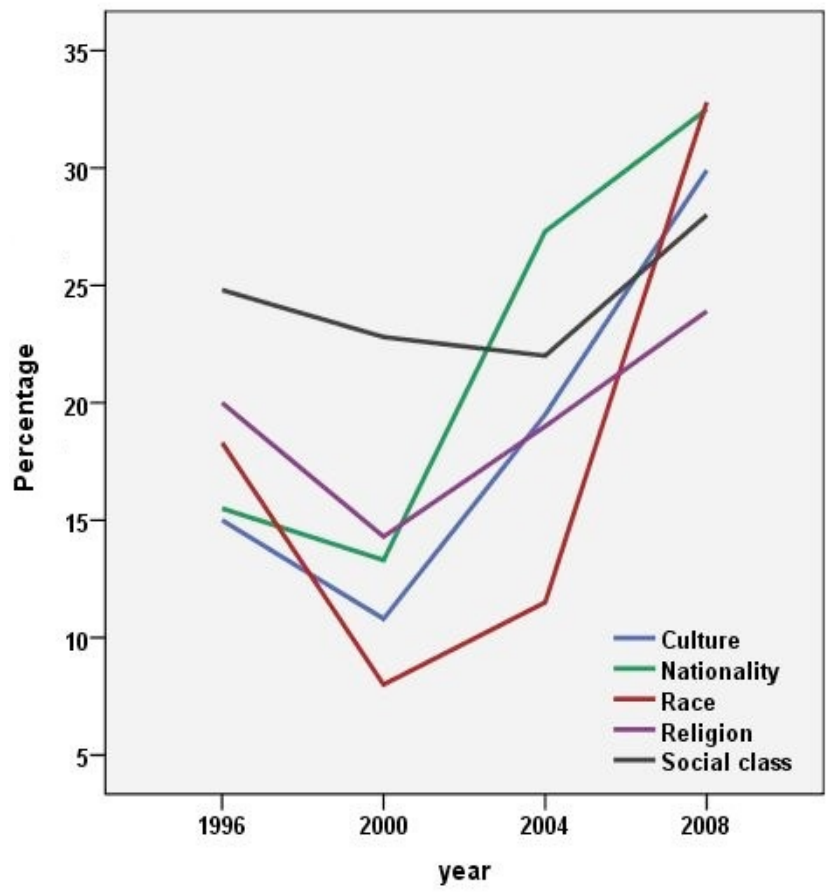

Fig. (4). Percentages for "many foreign people living in their neighbourhood", over time.

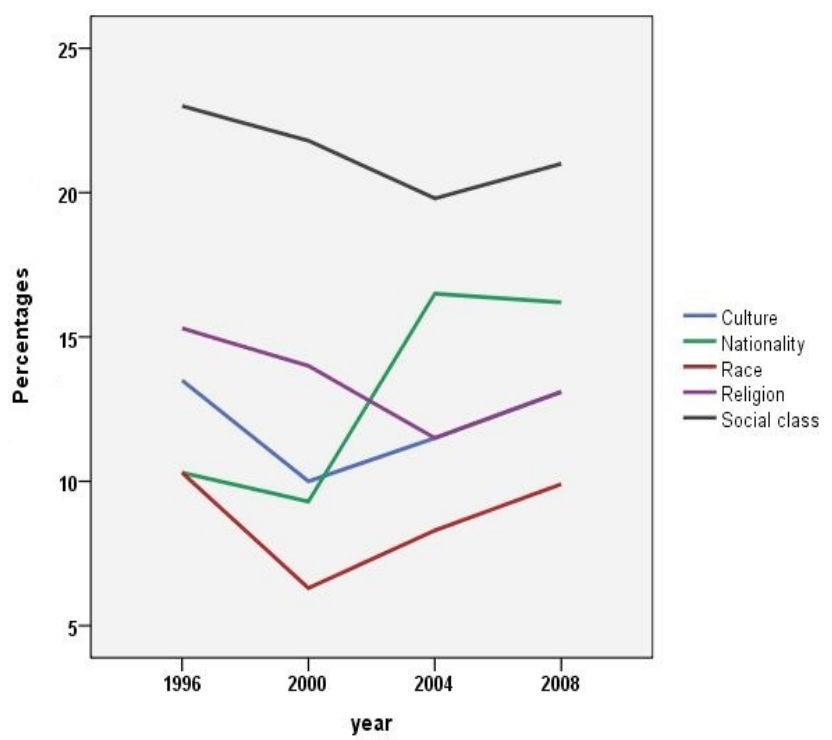

Fig. (5). Perception of "many immigrants" with respect to friendship.

Over the entire study period, social class registered high percentages for all but decreasing, perhaps implying that the economic situation of the individual is not the main factor associated with otherness. The growth associated with nationality indicates that this is major factor of otherness. The other categories (race, religion, and culture) seem not to have strong effect on the vicinity, and growth was very small but constant, mainly from the year 2000 on. This trend continued, though with minor percentages, with respect to the other categories, thus showing an increase in daily relationships. The comparison with the previous category indicates that the perception of foreigners in the city as a whole was greater than in the neighbourhood, that is, the growth index was almost three-fold when the entire city was considered.

The application of $\chi^{2}$ test indicates significant statistical differences between men and women $\left(\chi^{2}=6.959, \mathrm{p}=0.031\right)$, wherein the men had few immigrant friends and the women were associated with many immigrant friends. Also, using the categories of age, the $\chi^{2}$ test provided no differences between these categories, but the category of age with many immigrant friends was 14-16 years. Another question that completes the perception of otherness concerns the number of foreign people in the working or educational environment, and corresponds to the daily life at work (the previous question was about the living environment). The relations in these spheres of activity are important due to the great number of hours spent together each day in a small space. The question was: "Do you think that there are many foreign persons, few, or none in your working or educational environment?" From 2000, there was a growth of immigrants in the working or educational environment with respect to culture, nationality, race, and religion, but social class remained almost at the same percentage. Nationality registered the most growth, and the percentage in 2008 was twice that of 2000. This shows a great diversity of people in these neighbourhoods, and otherness was not perceived in this category. Social class appears as the strongest factor governing friendship and constitutes a stable factor over time, i.e. the youths have many friends from different social classes (Fig. 6). Percentages for "many immigrants living in the working or edu-

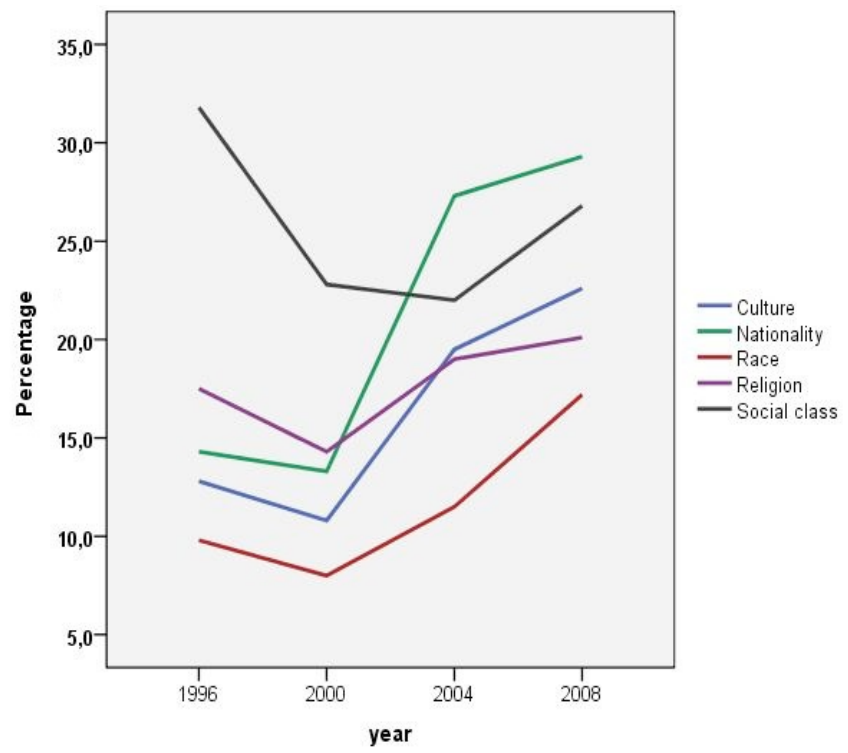

Fig. (6). Percentages for "many immigrants living in the working or educational environment", over time. 
cational environment", over time. The $\chi^{2}$ test provided no statistically significant differences between sexes in the perception the otherness with respect to the environment of the people polled $\left(\chi^{2}=4.214, \mathrm{p}=0.122\right.$. Also, there were no statistically significant differences by age $(\chi 2=4.214, \mathrm{p}=0.122)$.

\section{DISCUSSION AND CONCLUSIONS}

Spain in the 1960s had many inhabitants who emigrated to other countries, to Latin America first and then to certain European countries later. This phenomenon ended in the 1980 s, when many people returned to Spain to retire, often bringing children back, also. From the 1980s, Spain began to receive large numbers of immigrants, due to a high economic rate of growth until the start of the last economic crisis. From 2000 on, the massive arrival of immigrants has been provoking xenophobic perceptions. This study examines the perception of "otherness" among the youth in the city of Granada and perceptual transformation over time. The results indicate that, in the 1999-2004 period, the immigrants came from North Africa for the most part, but in 2008 decreased to half. Immigration from Central Africa continuously declined to very low percentages (from $25.4 \%$ in 1996 to $7.3 \%$ in 2008). Latin American immigration, almost negligible in 1996 and 2004, grew to the quarter of the entire immigration in 2008, apparently due to a shared language (Spanish) and failing economies in Latin America. The other areas (Asia and Europe) grew in 2008, but by small percentages, possibly for the economic boom in Spain during the period 2004-2008. Probably, this situation in Granada is similar to other areas of Spain [20-22]. The youths perceive otherness fundamentally due to social class, but other categories such as nationality or race are influential. The growth of otherness in each category analysed (nationality, social class, race, and religion) was noticeable and continuous.

Daily life constitutes a strong indicator to detect a nonstructural xenophobia. This phenomenon was detected by means of three categories quantifying this situation. The analysis of the question "Are there many foreign people living in your neighbourhood?" reached an inflexion point in 2000 , with a continuous growth in the following years, mainly for nationality, race, and culture. Also, social class proved to be the most important factor, with high percentages over time. These results indicate that otherness is hardly associated with cultural features, so classifying people as belonging a group as individually. This feature is general among the young people living in Granada, given that there were not differences in perception, either for sex or for age range. The question "Do you have foreign friends?" differs from the previous one in that it is positive, that is, to have friends is a virtue rather than a flaw. The continuous decrease in social class indicates that this category it is not so important as it was previously or maybe the goodness of the economy in recent years diminished the problem. Nevertheless, in 2008, nationality appeared as an emerging factor that prevents friendship between the Granada youths and immigrants, and, together with other indicators, indicates that the daily relationship in the same neighbourhood attenuates the otherness. In terms of sex, men have few foreign friends while women have many. This perception did not change for the age ranges. The working or educational environment showed a great diversity of people, but the young people had few friends of another race or religion, which, together with nationality and the other categories, implies that race and religion are the major factors of otherness in the working or educational environment. The present survey has detected the perception of otherness, but not the underlying causes. A plausible hypothesis is that the growth of immigration produces a growth in this perception, but it is possible that the youths in Granada are becoming more xenophobic. Probably, as more immigrants come to the city, xenophobia will increase, as a feedback effect.

\section{ACKNOWLEDGEMENT}

None declared.

\section{CONFLICT OF INTEREST}

None declared.

\section{REFERENCES}

[1] Moreno JF. Inmigración y Estado de Bienestar en España. Política y Sociedad 2007; 2(44): 171-84

[2] Suárez L. Rebordering the Mediterranean: Boundaries and Citizenship in Southern Europe. New York, United States: Berghahn Books 2004.

[3] Tézanos JF. Nuevas tendencias migratorias y sus efectos sociales y culturales en los países de recepción. Doce tesis sobre inmigración y exclusión social. REIS 2007; 117: 11-34.

[4] AA.VV. Observatorio Permanente Andaluz de las Migraciones. Informe Anual. Andalucía inmigración 2008. Sevilla, Spain: Dirección General de Coordinación de Políticas Migratorias 2008.

[5] Urdiales ME, Menéndez M. La Población Extranjera en Andalucía. Cuadernos Geográficos de la Universidad de Granada 2005; 36: 169-84.

[6] O'Rourke KH, Sinnott R. The determinants of individual attitudes towards immigration. Eur J Pol Econ 2006; 22: 838-61.

[7] Hansen JD. Immigration and income redistribution in welfare states. European Eur J Pol Econ 2003; 19: 735-46.

[8] Municipality of Granada. Padrón Municipal a 1 de enero de 2005. Granada, Spain: Municipality of Granada 2005.

[9] Freeman RB. Immigration from poor to wealthy countries: Experience of the United States. Eur Eco Rev 1993; 37(2-3): 443-51.

[10] Van Oudenhoven JP, Ward C, Masgoret AM. Patterns of relations between immigrants and host societies. Int J Intercult Rel 2006; 30(6): 637-51.

[11] Agudelo-Suárez A, Gil-González D, Ronda-Pérez E, Porthé V, Paramio-Pérez AM, Garí A. Discrimination, work and health in immigrant populations in Spain. Soc Sci Med 2009; 68(10): 186674.

[12] Jiménez F. Juventud y racismo. Actitudes y comportamiento en Granada. Granada, Spain: IMFE 1997.

[13] Jiménez F. La inmigración marroquí en Granada: su imagen y percepción por los jóvenes granadinos. Estudios Geográficos 2006; 261(LXVII): 549-78.

[14] Jiménez F. Alteridad y religión excluyente hacia los inmigrantes: el caso de Granada (España). Ra Ximbai: Revista Científica de sociedad, cultura y desarrollo sostenible 2008; 3(4): 713-35.

[15] Brodkin K. Xenophobia, the state and capitalism. Am Ethnol 2005; 32(4): 519-20.

[16] Castles S, Miller, M. The age of migration. New York, United States: The Guilford Press 2003.

[17] Jiménez F. Migration in Spain: Andalucía and Granada. Int Res Soc Polit Econ 2009; 1: 94-107.

[18] Nannestad P. Immigration and welfare states: A survey of 15 years of research. Eur J Polit Econ 2007; 23(2): 512-32.

[19] United Nations. Internacional Migration Report 2006: Global Assessment. New York: United Nations Press 2009. 
[20] Jiménez F. Las implicaciones para España de la nueva identidad europea y los conflictos étnicos. Espacio Público 2007; 19: 214-36.

[21] Rinken S, Pérez M. Opiniones y actitudes de la población andaluza ante la inmigración. Sevilla, Spain: Junta de Andalucía Press 2007.
[22] Rocha I. The implications of spanish-moroccan governmental relations for moroccan immigrants in spain spanish-moroccan governmental relations and moroccan immigrants. Eur J Migr Law 2005; 4(7): 413-34.

(C) Esquivel et al.; Licensee Bentham Open.

This is an open access article licensed under the terms of the Creative Commons Attribution Non-Commercial License (http://creativecommons.org/licenses/by-nc/3.0/) which permits unrestricted, non-commercial use, distribution and reproduction in any medium, provided the work is properly cited. 